\title{
NOTAS SOBRE OS IMPACTOS DA PANDEMIA DO CORONAVÍRUS NO TRABALHO DOS/AS ASSISTENTES SOCIAIS
}

NOTES ON THE IMPACTS OF THE CORONAVIRUS PANDEMIC ON THE WORK OF SOCIAL WORKERS

\begin{abstract}
Maria Clara de Oliveira Figueiredo*a, Ana Patricia Maciel Senaa, Luana Marcia Barros Costaa, Aldir Alves Bezerra Juniora, Josefa Jacinta Alves Limaa, Larissa Rabeche Duarte Dias $^{a}$, Maria França da Silvaa, Francisco Wallyson Ferreira Lira ${ }^{a}$
\end{abstract}

\author{
Centro Universitário Dr. Leão Sampaio, UNILEÃOa \\ *E-mail: clarafigueiredo@leaosampaio.edu.br
}

\section{RESUMO}

Diante da Crise global do Novo Coronavírus, o mundo do trabalho tem sofrido intensas modificações. Nessa conjuntura, buscamos analisar como a Pandemia tem impactado no trabalho dos/das Assistentes Sociais. Para tanto, foi necessário discutir o Conceito de crise e suas repercussões socais; analisar a crise do trabalho na sociedade capitalista em meio a pandemia e pensar as principais repercussões para o trabalho dos/das assistentes sociais nos espaços sócioocupacionais. Trata-se de uma pesquisa bibliográfica do tipo narrativa e documental com abordagem qualitativa. Ressaltamos a importância de debates acerca das mudanças vivenciadas no cotidiano que impactam sobremaneira nas condições de vida dos/das usuários/as e de trabalho desses profissionais. Ao concebermos como fundamental a função social desses profissionais e compreendermos, no campo das demandas e respostas possíveis, a dinâmica cotidiana dessa categoria profissional, foi possível registrar sistematicamente os seus desafios e potencialidades diante desse contexto.

Palavras-chave: Saúde; Serviço Social; Coronavírus.

\section{ABSTRACT}

In the face of the global crisis of the New Corona Virus on the world, the work has undergone severe changes. In this context, we seek to analyze how the Pandemic has an impact on the work of Social Workers. For that, it was necessary to discuss the Concept of crisis and its social repercussions; analyze a labor crisis in capitalist society in the middle of the pandemic and think as the main repercussions for the work of social workers in socio-occupational spaces. This is a bibliographic research of the narrative and documentary type with a qualitative approach. We emphasize the importance of debates about the changes experienced in daily life that greatly impact users' living conditions and the work of these professionals. By conceiving the social function of these professionals as fundamental and understanding, no field of demands and possible answers, the daily life of this professional category, it was possible to systematically record their challenges and potential in this context.

Keyword: Work; Social Service; Pandemic of the New Coronavirus; 


\section{INTRODUÇÃO}

Nos primeiros meses de 2020 quase todos os países do mundo foram afetados pela pandemia do novo coronavírus que instaurou um processo de afastamento social. A expansão da pandemia provocou uma intensificação nas manifestações da Questão social ${ }^{1}$ o que, por consequência, levou os/as assistentes sociais, juntamente com outras classes profissionais, a enfrentar novos desafios.

Ampliação de jornadas de trabalho; diminuição de profissionais nos campos de atuação; realização de atividades sem equipamentos de proteção individual e, consequentemente, risco eminente de contágio e, a imposição da necessidade de reinvenção da prática profissional, são algumas das repercussões que passaram a atingir o cotidiano profissional.

Essa nova realidade trouxe à tona insegurança aos profissionais e a necessidade de uma maior discussão no âmbito da categoria profissional acerca dos rumos da profissão e da revisão das práticas operacionais. $\mathrm{O}$ fato é que rotinas foram totalmente reestruturadas e formas possíveis de atuação foram inseridas (como o teletrabalho). Nesse processo, tornou-se imperativo o (re)planejamento ativo das ações, além do agravamento das problemáticas sociais na vida dos/das usuários/as dos serviços e das políticas onde este profissional se insere.

Diante desse contexto, essa pesquisa foi desenvolvida com o objetivo geral de compreender de que modo a pandemia do novo Coronavírus influenciou a prática dos/das profissionais de Serviço Social. Para tanto, buscamos compreender o que é a covid-19 e como ela afetou o mundo do trabalho, quais desafios ela provocou na prática profissional dos/das assistentes sociais e as suas possibilidades de atuação.

A pandemia do novo Coronavírus tem afetado imensamente o convívio social em uma perspectiva global. Devido à abrangência desse fenômeno e das suas consequências sociais é fundamental a realização de estudos sobre esta temática que possibilitem aos profissionais que lidam com o público diverso uma maior compreensão da situação. Tendo isso em vista, deu-se início a realização de uma pesquisa que tentasse compilar de modo conciso um conjunto de informações que possibilitem ao leitor um melhor entendimento da situação atual.

${ }^{1}$ Essa Questão Social surge na transição do capitalismo concorrencial para o monopolista e surge primordialmente como uma reação a lógica capitalista exploradora e dominante (BEHRING, BOSCHETTI,2011). Esse conceito é amplamente discutido no Serviço Social expressa para Iamamotto (2001) desigualdades econômicas, políticas e culturais das classes sociais, decorrentes das disparidades nas relações de gênero, características étnicas raciais e formações regionais, colocando em causa amplos segmentos da sociedade civil no acesso aos bens da civilização. Destaca, ainda, que foram as lutas sociais que romperam

\section{METODOLOGIA}

O presente trabalho foi construído através da realização de uma revisão bibliográfica de tipo narrativa e documental em uma abordagem qualitativa. Para a realização dessa pesquisa foram selecionados livros, artigos, documentos e devido ao fato da atualidade da temática também foram utilizados sites e pesquisas oficiais de informações.

O motivo da escolha da realização de um trabalho moldado pela revisão bibliográfica de tipo narrativa se deu em decorrência da possibilidade de alcançarmos uma diversidade de informações de modo mais fluido e abrangent e, ao mesmo tempo, buscando compilar dados que envolvem o universo do Serviço Social. A partir desses dados é possível obter uma melhor definição da situação e dos conceitos que facilitam a nossa interpretação (LIMA e MIOTO, 2007)

Os artigos selecionados foram localizados em sua maioria na plataforma Scielo onde foram localizados 184 trabalhos que seguiram para análise, entretanto, alguns foram selecionados no Google Acadêmico. Também foram selecionados artigos do Centro de Medicina Baseada em Evidências de Oxford e do Imperial College London, estes escolhidos devido a imensa relevância que tiveram, sendo usados, por exemplo, a Organização Mundial da Saúde (OMS) em vários países como base para tomada de decisões durante a pandemia.

Os trabalhos foram selecionados com base nos parâmetros de seleção que são indicados por Lima e Mioto (2007): parâmetro temático, parâmetro linguístico, principais fontes e parâmetro cronológico. No primeiro parâmetro, selecionamos os trabalhos através dos seguintes descritores: Brasil; Covid-19 e Serviço Social. Esses passaram por uma leitura de reconhecimento e os que mostraram pertinência ao tema trabalhado foram selecionados. Os trabalhos foram pesquisados em dois idiomas: Português e Inglês. Como o tema aqui tratado é extremamente atual, os selecionados encontram-se em pequeno intervalo de tempo, publicados entre janeiro de 2020 a julho de 2020 .

Além desses trabalhos, foram analisados documentos publicados pelo Conselho Federal de Serviço Social e pelo Governo Brasileiro, por exemplo os

o domínio privado nas relações entre capital e trabalho, extrapolando a Questão Social para esfera pública exigindo a interferência do Estado para o reconhecimento e a legalização de direitos e deveres dos sujeitos sociais envolvidos. Por fim, aponta que na perspectiva por ela assumida, a Questão Social não se identifica com a noção de exclusão social, hoje generalizada, dotada de grande consenso nos meios acadêmicos e políticos. 
relatórios do Instituto de Pesquisa Econômica Aplicada e a portaria $\mathrm{n}^{\circ} 639$. Foram priorizados documentos publicados por órgãos oficiais como a OMS e o Ministério da Saúde para garantir maior confiabilidade aos dados coletados.

E para enriquecer ainda mais a pesquisa, foram usados autores que contribuíram com a temática, tais como Raquel Raicheles (2011), Behring e Boscheti (2011), Marilda Iamamoto $(2007 ; 2001)$ e Ricardo Antunes (2015).

\section{RESULTADOS E DISCUSSÃO}

\section{CRISE DO CAPITAL MUNDIALIZADO E SUAS CONSEQUÊNCIAS SOCIETÁRIAS}

Com o processo de globalização, as crises econômicas impactam todos os países do mundo, obedecendo suas particularidades. A Crise da década de 1970 que se alastra para os dias atuais é, nas palavras de Meszáros (2009), estrutural, ou seja, não se refere apenas a um ramo de produção, mas atinge às diversas dimensões da vida humana, tendo como substância central a separação, cada vez mais aprofundada, entre a produção para atender as necessidades sociais e a autorreprodução alienada e incontrolável do capital. As formas de superação dessa crise são cada vez mais desumanas diante do avanço das tecnologias e substituição da mão de obra humana por máquinas e das mais aprimoradas formas de coisificação do homem.

Observa-se ocorrências simultâneas: verifica-se a desproletarização do trabalho industrial e fabril e a intensificação do trabalho parcial, precário e temporário, que marca a sociedade dual do capitalismo avançado (ANTUNES, 2015, p.211).

É possível observar que nesse processo de flexibilização o trabalhador perdeu, especialmente, a estabilidade e a segurança, enfraquecendo sua capacidade de mobilização e organização política diante dos ditames do mercado de trabalho.

A crise do modo de produção impacta as políticas sociais, com a redução dos investimentos para as mesmas o que acarreta o sucateamento e precarização dos serviços nas políticas já existentes e consolidadas, deixando a população assalariada e de baixa renda em situação ainda mais vulnerável, o que aprofunda as expressões da Questão Social.

As políticas públicas no cenário neoliberal permanecem extremamente fragilizadas e seus usuários cada vez mais vulneráveis às consequências da exploração. Todas as fragmentações do campo trabalho tem se vinculado as logicas neoliberais impostas no campo social pela política.
Sem dúvidas estamos diante de um contexto desafiador para a humanidade, uma vez que

As últimas quatro décadas no Brasil e no mundo desenha-se um momento singular e muito significativo da trajetória moderna e da caminhada da humanidade: o período da emergência de um novo tempo do viver e do refletir humanos. Tempo da falência dos ambiciosos projetos revolucionários, da fragmentação das grandes estruturas teóricas, do refluxo das tentativas de emancipação humana, da banalização da violência, da relativização do mundo do trabalho, da desorientação ideológica, da hipercomplexidade dos sistemas sociais, do domínio da alta tecnologia, da comunicação instantânea, do mundo da informação digital e da realidade virtual. Tempo, em poucas palavras, de configuração de uma nova etapa da sociedade (BEDIN, NIELSSON, 2013, P.27).

Ressaltamos que tais mudanças que já vinham sendo desenvolvidas nessas últimas décadas encontram agora um novo cenário de crise eminente precipitada pela Pandemia do novo Coronavírus cujos impactos são globais.

\section{PANDEMIA DO NOVO CORONAVÍRUS E AS NOVAS TRANSFORMAÇÕES NO MUNDO DO TRABALHO}

O Covid-19 é uma doença causada por meio do mais recente vírus dentre os Coronavírus, o SARS-CoV2 (WHO, 2020). Esse vírus foi descrido pela primeira vez no final de 2019 na província de Wuhan na China (LIMA, 2020) e se alastrou rapidamente, contagiando mais de 180 países (PGT WALER, 2020).

O novo Coronavírus já infectou aproximadamente mais de 15 milhões de pessoas, sendo que desse total, mais de 2,2 milhões ocorreram somente no Brasil (BRASIL- Ministério da Saúde, 2020) vitimando ao redor do mundo mais de 425 mil pessoas (WORLDOMETER, 2020).

A Covid-19 se espalha entre pessoas através de pequenas gotas que são expelidas pela boca e pelo nariz durante a fala ou espirros (WHO, 2020), desse modo se alastra com grande facilidade em ambientes que possuem grande quantidade de pessoas.

Além disso, a letalidade da Covid-19 tem um crescimento exponencial, logo, devido à sua rápida disseminação, pode acabar superando a capacidade do sistema de saúde nacional. Assim sendo, muito países optaram por implementar medidas de distanciamento social com o intuito de não ocasionar um pico de contaminação muito superior às capacidades nacionais. 
Desse modo, podemos perceber que a pandemia é agravada devido às condições sociais da população e do País. É importante salientar que esse agravamento não se restringe apenas a área da saúde, ela atinge a sociedade como um todo, nas áreas educacionais, sociais, econômicas e psicossociais da população.

Estima-se que até metade da população irá sofrer problemas de saúde mental durante a pandemia, sendo alguns mais leves, como medo e sentimento de solidão até os mais graves como o aumento de tentativas de suicídio, hipocondria, depressão, estresse pós-traumático, consumo excessivo de álcool e comportamento violento (FIOCRUZ, 2020).

A economia mundial também será profundamente afetada, a previsão é que o Produto Interno Bruto (PIB) mundial retraia 3,2\%, o que representa 8,5 trilhões de dólares (ONU, 2020). O Brasil vinha em uma onda tímida de crescimento nos últimos três anos e diante da Pandemia economistas estão prevendo a retração em $5,4 \%$ devido ao fato de que mais de $90 \%$ dos postos de trabalho no Brasil foram atingidos pelas medidas de distanciamento social (ONU, 2020). Todo o setor produtivo foi afetado, havendo diminuição de $92,9 \%$ na produção de alguns setores em comparação com o mesmo período do ano passado e uma previsão de retração de 36,1\% em toda a indústria (IPEA, 2020).

Essa crise econômica atinge diretamente a população mais vulnerável. Em meados de 2020, já foram perdidos mais de 1,5 milhões de empregos formais, enquanto nesse mesmo período em 2019 haviam sido gerados mais de 150 mil empregos (BRASIL, 2020).

Com esse aumento do desemprego, existe a tendência de que um maior número de pessoas passe a vivenciar situações de vulnerabilidade social. Estima-se que até o final desse ano mais 86 milhões de crianças irão sofrer com a fome no mundo (UNICEF, 2020).

Associemos a todo esse processo a reestruturação das rotinas de trabalhos tanto na área da saúde cujos profissionais estão diretamente lidando com os casos da Covid-19 e com o risco de contaminação em níveis mais graves, como naqueles que são considerados essenciais para a superação de situações de pobreza e vulnerabilidade, tais como os serviços da Assistência Social, Habitação, Trabalho e Renda, Esporte, Cultura e Lazer cujas ações são imprescindíveis para melhoria da qualidade de vida das pessoas.

ASSISTENTE SOCIAL COMO TRABALHADOR ASSALARIADO: notas sobre os desafios, alternativas $e$ possibilidades em tempos de Pandemia

Averiguar a laboração ocupacional do/da assistente social é pensar seu trabalho a partir dos processos históricos, evidenciando as alterações na produção e reprodução das relações capitalistas que determinam transmutações nas condições e relações de trabalho. A incitação está em compreender a centralidade do trabalho mediante transformações acionadas pelo capitalismo.

Nessa complexa configuração do trabalho, insere-se a práxis do Serviço Social que se apresenta nessa dinâmica contemporânea dotado de dimensões teórico-metodológicas, técnico-operativas e éticopolíticas do fazer profissional bem como as condições materiais de objetivação desse trabalho.

Iamamoto (2007) absorve dessa reflexão de cunho marxista que o trabalho desses profissionais enquanto trabalhadores assalariados possui uma dupla dimensão. Nesse sentido, afirma a autora:

Em decorrência, o caráter social desse trabalho assume uma dupla dimensão: a) enquanto trabalho útil atende a necessidades sociais (que justificam a reprodução da própria profissão) e efetiva se através de relações com outros homens, incorporando o legado material e intelectual de gerações passadas, ao tempo em que se beneficia das conquistas atuais das ciências sociais e humanas; b) mas só pode atender às necessidades sociais se seu trabalho puder ser igualado a qualquer outro enquanto trabalho abstrato - mero coágulo de tempo do trabalho social médio - , possibilitando que esse trabalho privado adquira um caráter social (2007, p. 421).

Nesses termos, esse profissional ingressa no mercado de trabalho possuindo competências e habilidades especializadas, conquistadas por meio de formação universitária, porém, só pode entrar em ação se dispuser de meios e instrumentos de trabalho que, não sendo de propriedade do/da assistente social, devem ser colocados à sua disposição pelos empregadores institucionais: recursos materiais, humanos, financeiros, para o desenvolvimento de programas, projetos, serviços, benefícios e de um conjunto de outras atribuições e competências, de atendimento direto ou em nível de gestão e gerenciamento institucional (RAICHELIS, 2011).

Em um sentido mais amplo, as ações, serviços, projetos e benefícios que os/as assistentes sociais operacionalizam, obedecem às necessidades sociais que são postas coletivamente, bem como às relações sociais e conflitos orquestrados em torno dessas necessidades para seu devido enfrentamento, seja por parte do Estado, da Sociedade Civil ou dos movimentos sócias. Assim sendo, esse profissional necessita está sintonizado com os 
movimentos conjunturais da sociedade no sentido de absorvê-los, interpretá-los, analisá-los criticamente para operacionalizar as suas respostas nos seus espaços de trabalho, os quais estão imbuídos de uma racionalidade que os particulariza.

A crise desencadeada pela covid-19 tem demonstrado que a desigualdade social é fator determinante na circulação do vírus e no agravamento das condições de vida. Assim, pensar estratégias de trabalho diante da reconfiguração do cotidiano é fator preponderante para o/a assistente social, pois estamos inseridos no contexto de luta pela superação dessas desigualdades e dos diversos tipos de violação de direitos por meio de ações individuais e coletivas.

De acordo com o Conselho Federal do Serviço Social (CFESS), para conter os impactos do Coronavírus no trabalho do/a assistente social, é importante que se assumam estratégias cotidianas nos seus diversos espaços e nas diversas regiões do País, seguindo rigorosamente as indicações e protocolos dos órgãos sanitários de saúde pública, além de observar as orientações no âmbito dos órgãos empregadores. Em nota o CFESS (2020, p. 2) manifesta:

Diante dessa situação, orientamos aos/às profissionais que negociem coletivamente junto às chefias o revezamento das escalas de trabalho, possibilitando a redução de presença física nos serviços sem o comprometimento do atendimento à população

Assim, para adaptar-se ao contexto da Pandemia e suas consequências, a profissão tem passado por um reordenamento no que tange à organização e estruturação dos seus processos de trabalho em seus diversos espaços. Não cabe aqui tratarmos de cada espaço especificamente, mas de propor uma reflexão ampla centrada no direcionamento ético-político das ações profissionais nos diversos espaços.

É razoável compreendermos que o novo Coronavírus tem uma função heurística de explicitar, de modo contundente, as profundas fragilidades das sociedades capitalistas revelando a natureza nefasta do Estado neoliberal que opera a lógica da desvalorização da vida.

O que se constata é que no país a insegurança e precariedade do trabalho (e da vida) convivem com a erosão do sistema público de proteção social, caracterizada pela retração dos investimentos públicos no campo social e pela crescente subordinação das políticas sociais às políticas de ajuste da economia, e sua perspectiva privatizadora e refilantropizadora (YAZBEK,
1995, p. 8)

Diante desse terreno, o cenário que estamos atravessando, exige a participação efetiva dos/as assistentes sociais ao enfrentamento dessa nova realidade buscando trabalhar questões relativas à humanização no atendimento, fortalecimento de vínculos familiares, enfrentamento a violação de direitos e mesmo de estudos e avaliação social para concessão e planejamento de políticas, serviços e de benefícios sociais.

Mas como atuar nesse contexto diante das medidas de distanciamento e de proteção garantindo o acesso dos usuários aos serviços? Nosso ponto de partida é reconhecer dois pontos fundamentais:

Primeiro: que de acordo com a Lei de Regulamentação da Profissão (Lei 8.662/1993) e com o Código de Ética Profissional, não podemos negar atendimento à população. No artigo $3^{\circ}$ do nosso Código de Ética Profissional, consta que é dever do/a assistente social, na relação com a população usuária, "participar de programas de socorro à população em situação de calamidade pública, no atendimento e defesa de seus interesses e necessidade"; e,

Segundo: no que tange as condições éticas e técnicas adequadas para a realização desse trabalho, conforme disposto na Resolução CFESS n 493/2006, em que o local de atendimento destinado ao assistente social deve ser dotado de espaço suficiente, para abordagens individuais ou coletivas, conforme às características dos serviços prestados, pois é direito dos/as assistentes sociais, conforme artigo $7^{\circ}$ do Código de Ética: “a dispor de condições de trabalho condignas, seja em entidade pública ou privada, de forma a garantir a qualidade do exercício profissional”.

Considerados esses dois pontos, constatamos que necessidades reais da vida cotidiana dos usuários são respondidas com mecanismos que combinam ações individuais e coletivas com políticas, serviços, projetos, programas e benefícios sociais que devem assegurar seus direitos básicos.

Destacamos aqui nomenclaturas que traduzem formas de trabalho que apesar de não serem recentes passam a ser amplamente disseminadas no momento atual, tais como o Trabalho Remoto, Home Office e Teletrabalho.

Vale destacar que Trabalho à distância, trabalho remoto, trabalho em casa e teletrabalho são considerados sinônimos da expressão home office (IGBARIA, TAN, 1998; MELLO, 1999; JARDIM, 2003). Em tradução livre, significa "trabalho em casa".

Associado às mudanças tecnologias e automação progressiva essa forma de trabalho tem grande potencial de se consagrar em diversas áreas de atuação no Brasil e 
no mundo.

A posição do CFESS em relação a essa forma de atuação na profissão é a de que certas atividades não são compatíveis com essa modalidade de trabalho. Assim, o conselho não indica sua adoção quando há possibilidade do atendimento presencial.

\begin{abstract}
Nesse momento de excepcionalidade, compreendemos que algumas atividades podem ser realizadas nas modalidades teletrabalho, videoconferência e on-line, para que nossas atividades não sofram descontinuidade. Contudo, entendemos que avaliação social para concessão de benefícios sociais, bem como estudo social e parecer social, não devem entrar no rol dos procedimentos que podem ser executados à distância. Isso, porque a avaliação resultante dessas atividades depende da análise de elementos e circunstâncias concretas da realidade social, que não podem ser inferidos por meio da análise documental, dependendo também de outros procedimentos técnicos que devem ser operacionalizados (CFESS, 2020, p. 4)
\end{abstract}

Sabemos que apesar das indicações, o CFESS não tem autonomia para decidir os rumos da profissão nos locais de trabalho, essa decisão cabe aos organismos empregadores. Os profissionais precisam estar atentos às novas requisições em seus espaços de atuação, reinventar suas estratégias e metodologias de intervenção e acionar os conselhos e órgãos competentes quando suas condições de trabalho ferirem as suas normativas profissionais e seus direitos trabalhistas.

As exigências ainda são incertas, mas diante da ausência de controle efetivo da doença e da possibilidade de nos lançarmos de fato em um "novo normal", esse cenário nos convida a reflexão sobre as práticas profissionais no futuro. É certo que a insegurança em lidar com uso de tecnologias, altos níveis de estresse e ansiedade também serão assuntos que necessitam ser mais discutidos pela categoria e merecem especial atenção.

No campo das atribuições e competências profissionais, é necessário propor reflexões capazes de colocá-las em movimento, no movimento do cotidiano e, consequentemente, neste cenário tão desafiador.

Por essa razão, optamos por debater os principais desafios e possibilidades diante da Pandemia com foco em quatro tipos de ações, conforme Trindade (2012), que de modo geral sistematizam o exercício profissional dos/das assistentes sociais nos diversos espaços, resguardadas as suas particularidades.

Ações profissionais, procedimentos $e$ instrumentos de caráter individual para o atendimento direto aos usuários

Historicamente, esses profissionais se colocam na viabilização direta de serviços aos usuários através do contato direto. Nesse processo, a entrevista, o acolhimento, a própria visita domiciliar como instrumentos que demandam esse contato direto precisam ser repensados. É importante reconhecer que são ações imprescindíveis na constituição de vínculos e mesmo na troca de informações e de orientações para a garantia de direitos.

Pela natureza da nossa atuação profissional bem como por sermos profissionais de saúde, assim como médicos/as, enfermeiros/as, psicólogos/as, farmacêuticos/as, dentre outras categorias profissionais, precisamos atender diretamente à população. Isto implica que é necessário um maior rigor no processo de higienização e na utilização dos Equipamentos de Proteção Individual (EPI) e Equipamentos de Proteção Coletiva (EPC) (CFESS, 2020).

Isso nos leva a um velho debate que trata da precarização do trabalho já discutido neste artigo, uma vez que as condições de trabalho nem sempre são favoráveis. Nesse ponto, torna-se imperativo que a categoria se fortaleça e se mobilize coletivamente nos seus espaços de atuação para cobrar dos seus empregadores pela adequação desse atendimento.

Além disso, como já foi colocado é importante que os/as profissionais se mantenham vigilantes para ponderar junto às instituições empregadoras o exercício remoto, tendo em vista que determinadas ações individuais necessitam desse contato direto (presencial) para resguardar sigilo e conduzir melhor o atendimento.

\section{Ações profissionais, procedimentos $e$ instrumentos de caráter coletivo para o atendimento aos usuários dos serviços sociais}

Trabalhos em grupo, tais como palestras, grupos de atividades socioeducativas para diversos públicos estão previstos inclusive nas normativas das políticas e espaços em que esse/essa profissional se insere. Tais ações passam a ser revistas para evitar aglomerações e mais uma vez surge alternativa de executar remotamente, via redes sociais.

A mesma problemática discutida no ponto anterior surge aqui: a do preparo desses/dessas profissionais, do manejo dessas tecnologias e da reinvenção dessas metodologias. Nesse ponto surge um outro debate, o da inclusão digital e nele cabe a reflexão sobre o nosso público que é considerado carente e que vive a margem desse progresso tecnológico. 
Esbarramos nos recursos necessários, nas formas educativas de inclusão digital que não é homogênea dentre os públicos que atendemos no que tange aos recortes de gênero, sexualidade, classe, raça, etnia, geração etc. É fato que boa parte desse trabalho foi suspenso nessa conjuntura, mas até quando? Nós estamos sendo a cada dia levados a refletir diante dessas incertezas.

Ações profissionais, procedimentos $e$ instrumentos de caráter administrativo-organizacional, utilizados na articulação inter e intra-institucional e na organização e gestão dos serviços sociais

Retratamos aqui os/as profissionais que atuam nas estruturas administrativas, de planejamento e organização dos serviços. Temos nessa dimensão o manejo de instrumentos diferentes daqueles com os quais esses profissionais lidam com o público diretamente.

Geralmente, são ações ligadas aos sistemas de gestão das políticas. Aqui podemos encontrar dois tipos de profissionais: 1) aqueles que atuam apenas na gestão e administração que podem nesse momento serem realizados com mais tranquilidade na modalidade remota; e, 2) aqueles que realizam várias dessas ações ao mesmo tempo, ou seja, fazem atendimento direto seja em grupo ou individual e executam o trabalho administrativo, burocrático, de planejamento e de articulação inter e intrainstitucional.

Quando pensamos no volume das demandas que frequentemente chegam a esses/essas profissionais e, nesse cenário, se agigantam diante das iniquidades sociais aprofundadas, temos uma indicação de extrema sobrecarga de trabalho.

De fato, são diversas situações a serem pensadas, mas todas vão trazer desafios a serem enfrentados no campo da insegurança, do despreparo e da gestão das incertezas por parte dos órgãos empregadores sejam eles públicos ou privados.

Ações profissionais, procedimentos e instrumentos de formação profissional, de capacitação e pesquisa

Nesse ponto, profissionais que trabalham em instituições de ensino em diversos níveis ou aqueles ligados às entidades representativas da categoria necessitaram também repensar suas metodologias de ensino e de acesso.

Disciplinas revistas, atividades suspensas, metodologias que se tornam inviáveis, comunicação via redes sociais intensificada, e novas plataformas de acesso levaram instituições e profissionais a um processo de reestruturação. O maior desafio: formar com qualidade.
O Estágio Supervisionando como etapa necessária para a formação em Serviço Social e imprescindível para a articulação teoria e prática também precisou sofrer significativas mudanças diante do isolamento social que foram desde a suspensão a postergação das atividades.

A ABEPSS identifica que este contexto cria uma série de situações que repercutem diretamente na Supervisão de Estágio: 1) Universidades públicas e privadas, com cursos presenciais, que estão com atividades interrompidas, total ou parcialmente, o que implica a não realização de Supervisão Acadêmica, mas que há a manutenção das/os estagiárias/os em campo, apenas com o acompanhamento presencial das atividades de estágio pela/o do Supervisor de Campo; 2) Universidades públicas ou privadas, com cursos presenciais, que estão com atividades interrompidas, o que implica a não realização de Supervisão Acadêmica, mas que há a manutenção de estagiários/as em campo, apenas com o acompanhamento do/a Supervisor/a de Campo por teletrabalho ou não; 3) Universidades com cursos presenciais, que estão desenvolvendo as atividades acadêmicas de maneira remota, o que significa a realização da Supervisão Acadêmica "por aulas remotas", com a manutenção de estagiários/as em campo, com a supervisão direta e presencial do/a Supervisor/a de Campo; e, 4) Manutenção de estagiários/as em campo de estágio, sob supervisão direta do/a supervisor/a de campo, como condição para a manutenção da bolsa, quando se trata de estágio, não obrigatório e/ou obrigatório, nas áreas consideradas essenciais. Essa diversidade de situações nos mostra intensas fragilidades na formação profissional nacionalmente.

No campo da pesquisa, metodologias de coleta de dados também foram revistas. As problemáticas se complexificaram ainda mais exigindo conhecimentos aprofundados e amplos, sobretudo, aqueles que nos aproximam de outras áreas do conhecimento apontando para uma maior integração de saberes.

A nossa profissão está transitando assim como as demais para um novo tempo, isso exige e exigirá do pensamento crítico maiores reflexões e debates e uma formação cada vez mais atenta. Os/as profissionais que lidam com a formação profissional em todos os níveis, intelectuais e pesquisadores/as estão se deparando na prática com uma mudança de paradigmas que efetivamente vai exigir uma qualificação ainda maior.

\section{CONSIDERAÇÕES FINAIS}

Em virtude dos fatos explicitados acima, o trabalho dos assistentes sociais, ao logo da sua gênese, passou por muitas transformações, nosso campo de luta 
sempre foi pautado por muitos desafios e transformações das práticas a partir das novas demandas. Como menciona Marilda Iamamoto (2007) os assistentes sociais precisam ser prepositivos, fazer uma leitura real da realidade e dar respostas reais para demandas apresentadas.

Em todo esse contexto o Serviço Social como profissão inscrita nas relações sociais compreende que há uma Questão Social que surge nos moldes do modo de produção capitalista e sua interpretação perpassa a esfera das lutas de classe que integram determinantes objetivos os quais condicionam a vida dos sujeitos.

Esses condicionantes são as expressões da Questão Social que se metamorfoseiam a partir das novas formas de exploração, precarização do trabalho e da vida humana. No campo profissional, além disso, anuncia-se uma disputa na condução das políticas econômicas e sociais que se acentua no advento do neoliberalismo.

Essa leitura da realidade, descrita acima, conota que a pandemia do novo coronavirus, atinge a nossa profissão e os usuários das políticas, gerando novas expressões dessa Questão Social que nos coloca no desafio de criar estratégias no coletivo e para o coletivo na busca de preservar a integridade humana do ser social.
Contudo, mesmo diante dos cenários desfavoráveis, os profissionais, gestores, políticos, cientistas e intelectuais repensam novas formas de gerir a vida de modo a preservá-la. As famílias e comunidades inteiras passam a repensar suas relações, pois elas são atravessadas pela quebra de vínculos, lutos reais e simbólicos, tendo que produzir valor mesmo diante dos desgastes, pois o capitalismo não para, nem permite que a força de trabalho pare.

O sofrimento, o medo, as incertezas atingem a todos mais de modos diferentes, uns vão conviver com a pobreza, o desemprego, a precarização dos serviços de saúde e assistência de forma mais incidente, principalmente no Brasil, em que a proteção social encontra-se negligenciada pelo estado.

Um dos profissionais que estão na linha de frente no combate ao Covid 19, está o Assistente Social que é exposto a exaustão; frustração; a políticas que funcionam com poucos recursos; e, com vidas humanas. Assim, estamos diante de uma realidade mutável, instável, e somos desafiados a seguir na luta intransigente pela afirmação cotidiana de direitos da população assistida.

\section{REFERÊNCIAS}

ABEPSS. (org). Nota da associação brasileira de ensino e pesquisa em serviço social referente ao estágio supervisionado no período de isolamento social para o combate ao novo coronavírus (covid-19). Brasília (DF), 03 de abril de 2020 .

ANTUNES, R.Adeus ao trabalho? Ensaio sobre as metamorfoses e a centralidade do mundo do trabalho. São Paulo: Cortez, 2015.

BBC NEWS/Brasil. Coronavírus : o mapa que mostra o alcance mundial da doença. Disponível em: < https://www.bbc.com/portuguese/internacional-51718755 >. Acesso em: 24 jul 2020.

BEDIN, G.A; NIELSSON, J.G. A crise da década de 1970:observações sobre as ideias neoliberais e suas consequências. In: COSTA, L, C; NOGUEIRA, V.M.R; SILVAV.R; org. A política social na américa do sul: perspectivas e desafios no século XXI [online]. Ponta grossa: Editora UEPG, 2013, P.27-41.

BEHRING, Elaine Rosseti; BOSCHETTI, Ivanete. Política social: fundamentos e história. $9^{\circ}$ ed. São Paulo: Cortez, 2011.
BRASIL- Ministério da Economia. Queda nas admissões influencia saldo de empregos formais do caged até abril de 2020. Disponível em:< https://www.gov.br/economia/pt-

br/assuntos/noticias/2020/maio/queda-nas-admissoesinfluencia-saldo-de-empregos-formais-ate-abril-de2020>. Acesso em: 12 jun. 2020.

BRASIL- Ministério da Saúde. Painel coronavirus. Disponível em:<https://covid.saude.gov.br/>. Acesso em: 23 jul. 2020.

BRASIL. Lei no 13.982, de 2 de abril de 2020. Disponível em:

<https://www.planalto.gov.br/ccivil_03/_Ato20192022/2020/Lei/L13982.htm>.

Acesso em: 24 jul 2020.

BRASIL. Medida Provisoria $\mathbf{n}^{0}$ 970, de 25 de maio de 2020. Disponível em: <http://www.planalto.gov.br/ccivil_03/_Ato20192022/2020/Mpv/mpv970.htm>.

Acesso em: 24 jul 2020.

BRASIL. Portaria $\mathbf{n}^{\mathbf{0}}$ 639, de 31 de março de 2020. Disponível 
em:<https://anec.org.br/wp-

content/uploads/2020/03/PORTARIA-N\%C2\%BA-639-

DE-31-DE-MAR\%C3\%87O-DE-2020-1.pdf>. Acesso em: 24 jul 2020.

CFESS. (Org.). Atribuições privativas do/a assistente social em questão. Brasília: CFESS, 2012b. Disponível em:

<http://www.abepss.org.br/arquivos/anexos/atribuicoes20 12completo-201804131236322062320.pdf>. Acesso em: 5 junho 2020.

Atribuições privativas do/a assistente social em questão. Brasília: CFESS, 2012 ( $1^{\circ}$ edição ampliada) Disponível

http://cfess.org.br/arquivos/atribuicoes2012-

completo.pdf Acesso em 3 de junho de 2019.

Código de Ética Profissional dos AssistentesSociais. Resolução CFESS nº. 273, de 13 de março de 1993 com as alterações introduzidas pelas Resoluções CFESS nº.290/94 e nº.293/94. Disponível em http://

cfess.org.br/arquivos/CEP_1993.

Resolução n.493, de 21 de agosto de 2006. dispõe sobre as condições éticas e técnicas do exercício profissional do Assistente Social e prevê algumas condições mínimas para o exercício da profissão. CFESS, 2006.

FIOCRUZ- Fundação Oswaldo Cruz. Saúde mental e atenção psicossocial na pandemia covid-19: Recomendações para Gestores. Disponível em: < https://portal.fiocruz.br/documento/saude-mental-eatencao-psicossocial-na-pandemia-covid-19-

recomendacoes-para-gestores>. Acesso em: 12 jun. 2020.

IAMAMOTO, M. V. A Questão Social no capitalismo. Revista Temporalis - Associação Brasileira de Ensino e Pesquisa em Serviço Social. Ano 2. No 3 (jan/jul.2001). financeiro, trabalho e questão social. São Paulo: Cortez, 2007.

IGBARIA, M.; TAN, M.The Virtual Workplace. Idea Group Publishing, London - 1998.

IPEA- Instituto de Pesquisa Econômica Aplicada. Boletim de acompanhamento setorial da atividade econômica.

Disponível

em:<https://www.ipea.gov.br/cartadeconjuntura/wp-
content/uploads/2020/05/200526_beltim_final_III.pdf>. Acesso em: 12 jun. 2020 .

JARDIM, C. C.da S. O Teletrabalho e suas atuais modalidades. São Paulo: LTR Editora, 2003.

LIMA, C. M. A. O. L. Informações sobre o novo coronavírus (covid-19). Colégio Brasileiro de Radiologia e Diagnóstico por Imagem; 04-2020 doi: http://dx.doi.org/10.1590/0100-3984.2020.53.2e1

LIMA, T. C. S. ; MIOTO, R. C. T. Procedimentos metodológicos na construção do conhecimento científico: a pesquisa bibliográfica. Rev. katálysis vol.10. Florianópolis, 2007 . Acesso em 26-03-2020. Disponível

em:

https://www.scielo.br/scielo.php?pid=S1414$49802007000300004 \% 20 \&$ script $=$ sci_arttext doi: https://doi.org/10.1590/S1414-49802007000300004

MELLO. Teletrabalho (Telework): O Trabalho em Qualquer Lugar e a Qualquer Hora. São Paulo: Qualitymark, 1999

MÉSZÁROS, I. A crise estrutural do capital. São Paulo: Boitempo, 2009, 133 p.

ONU- Organização das Nações Unidas. World Economic Situation and Prospects as of mid-2020. Disponível

em:< https://www.un.org/development/desa/dpad/publication/ world-economic-situation-and-prospects-as-of-mid2020/>. Acesso em: 12 jun. 2020.

PGT Walker, Whittaker, C; Watson, O; Baguelin, M; Ainslie, K; et al. O impacto global do COVID-19 e estratégias para mitigação e supressão. Colégio Imperial de Londres; 26-03-2020 doi: REDAÇÃO, O Estado de S. Paulo. Pandemia é maior desafio desde Segunda

Guerra, alerta ONU. Disponível em: $<$ https://internacional.estadao.com.br/noticias/geral,pand emia-e-maior-desafiodesde-segunda-guerra-alertaonu,70003256142>. Acesso em: 24 jul 2020.

RAICHELIS, Raquel. O assistente social como trabalhador assalariado: desafios frete às violações de seus direitos. Revista Serviço Social e sociedade. São Paulo,n.107,p.420-437,Jul./Set. 2011.

TRINDADE, Rosa L. Prédes. Ações profissionais, procedimentos e instrumentos no trabalho dos assistentes sociais nas políticas sociais. In: SANTOS, Cláudia Mônica dos, BACKX, Sheila e GUERRA, 
Yolanda. A Dimensão técnico-operativa no Serviço Social: desafios contemporâneos. Juiz de Fora, CAPES/Editora UFRJ, 2012, p. 69-102.

WHO- WORLD HEALTH ORGANIZATION. Q\&a on coronaviruses (covid-19). Disponível em: <https://www.who.int/emergencies/diseases/novelcoronavirus-2019/question-and-answers-hub/q-a-detail/qa-coronaviruses>. Acesso em: 12 jun. 2020.
WORLDOMETER. coronavirus pandemic. Disponível em:< https://www.worldometers.info/coronavirus/>. Acesso em: 23 jul. 2020

YAZBEK, MC. A Política Social brasileira nos anos 90: refilantropização da Questão Social. In Cadernos ABONG n 11, 1995. 